\title{
AMENDMENTS
}

\section{Author Correction: Super-resolved 3D tracking of cargo transport through nuclear pore complexes}

Rajdeep Chowdhury, Abhishek Sau and Siegfried M. Musser iD

Correction to: Nature Cell Biology https://doi.org/10.1038/s41556-021-00815-6, published online 10 January 2022.

In the version of this article initially published, there was a typographical error in Fig. $2 \mathrm{~g}$. The left-hand vertical axis label, now reading " $y(\mathrm{~nm})$ ", originally appeared as " $z(\mathrm{~nm})$." The change has been made to the HTML and PDF versions of the article.

Published online: 1 February 2022

https://doi.org/10.1038/s41556-022-00855-6

() The Author(s), under exclusive licence to Springer Nature Limited 2022

\section{Author Correction: Cell fate decisions are specified by the dynamic ERK interactome}

Alex von Kriegsheim, Daniela Baiocchi, Marc Birtwistle, David Sumpton, Willy Bienvenut, Nicholas Morrice, Kayo Yamada, Angus Lamond, Gabriella Kalna, Richard Orton, David Gilbert and Walter Kolch

Correction to: Nature Cell Biology https://doi.org/10.1038/ncb1994, published online 22 November 2009.

In the version of this article initially published, the Supplementary information section was missing the Matlab code used in this study. The code is now available in this notice.

Supplementary information is available in the online version of this article.

\section{Additional information}

Supplementary information The online version contains supplementary material available at https://doi.org/10.1038/s41556-022-00867-2.

Published online: 18 February 2022

https://doi.org/10.1038/s41556-022-00867-2

(c) The Author(s), under exclusive licence to Springer Nature Limited 2022

\section{Author Correction: Mapping paths through the nuclear pore complex}

Vasilisa Aksenova (D) and Mary Dasso (D)

Correction to: Nature Cell Biology https://doi.org/10.1038/s41556-021-00823-6, published online 10 January 2022.

In the revised version of this News \& Views now appearing online, the authors corrected the positioning and density of the rings with regards to the cargo trajectories (shown in shades of blue and green) to better reflect the data presented in the paper by Chowdhury et al. ${ }^{1}$. The orientation of the cytoplasmic and nuclear sides has also been flipped. The original and revised versions of Fig. $1 \mathrm{~b}$ appear below.

These changes have been made in the online version of the News \& Views.

\section{References}

1. Chowdhury, R., Sau, A. \& Musser, S.M. Super-resolved 3D tracking of cargo transport through nuclear pore complexes. Nat. Cell Biol. https://doi.org/10.1038/ s41556-021-00815-6 (2022). 